\title{
GENERAL CONSIDERATIONS REGARDING WHAT IS AND WHAT IS AIMING TO BE THE LOCAL POLICE
}

\author{
C. Leucea
}

\section{Crăciun Leucea}

Law and Economics Faculty, Social Sciences Department

Agora University of Oradea, Oradea, Romania

*Correspondence: Crăciun Leucea, Agora University of Oradea, 8 Piața Tineretului St., Oradea, Romania

E-mail: departament@univagora.ro

\begin{abstract}
The present paper aims to reveal the definitive elements; the particular and specific elements that are the structural and spiritual cause that have determined the birth, functioning and development of the local police entities. At the same time I wanted to motivate in my own version the reason of being, of existing and functioning of such a structure, as well as what they mean for the community, citizen and the administration of the town, of the locality. The answer to the question whether such a public institution was necessary or not, what is the spirit that it imprints at the level of the relation between the citizen and "the organ", service of order and public safety. What is different to what existed until the present day comes in front of the inhabitant of the town? The approach method of the issue, the behavior is different of what we have known so far.

Through systematizations and statements of the problem subsumed to the title of the article, the presentation, I wanted to outline the facet of the local police through which to offer a simple painting nevertheless with the many casts claimed by the corpus of the structure for a comprehensive and reflexive understanding of its ego in close connection with its Alter ego, that is the citizen.

The present article addresses both to the eager in the academic environment and also to the "common" citizen, indebted and willing to have a first and eloquent idea about what is and what aims to be this new public institution with judicial personality or in subordination of the local councils and which solves the daily problems of the citizens, which affect them directly or indirectly. Through the 7 (seven) abstract problems I appreciate that the discursiveness of the presentation will clear many aspects that at first sight could hardly be distinguished compared with the existence and functioning of the structures of national police.
\end{abstract}

Keywords: local police force, community, public service

\section{Introduction}

The consequences of the European integration over the system of Law in Romania manifest as significant as in other fields and in terms of what the local police represents, seen from the point of view of the organization, legal basis, action, recruitment, personnel, personnel training, transparence and prediction, in what exists and undertakes, internal and international cooperation and of course through the fact that it is subordinated to the community.

The activities of the local police are undertaken mainly in close connection with the population, the community, and its efficiency depends on the support of the latter. The trust of the population (of the community) in the local police is in close connection with the attitude and the behavior of the police regarding the community and particularly with the respect of 
the human community, the freedom and the fundamental rights of the person that are stated mainly in the European Convention on Human Rights ${ }^{1}$.

\section{The birth and the evolution of the structures of local (community) police}

The police serving the community (community policing) is an idea that took birth in the United Kingdom, where it meant the association of the entire community, particularly in order to prevent crime, but also detecting it.

This model was taken by many European countries and gained broad valences and with benefits for the citizens.

The assistance (the support) of the population (community) is the main mission of the community police. $^{2}$

The comprisal of various services throughout the objectives of the community police is different towards what we knew so far, meaning that it changes the role of the police, that, by ceasing to be a force used in the society, becomes an "organ" serving the latter. For some years in Europe has appeared a new tendency, to integrate the police in the civil society and to bring it closer to the population.

This purpose is reached through the development of the community police in several member states. One of the main used means consists in the awarding of a status as an "organ" of public service and not just a simple "organ" instructed to apply the law.

If it is wanted that this transformation remains not just a linguistic one, it is necessary to introduce a category of "services" within the actions of the community police, through the objectives of a modern democratic police. The assistance assured by the local (community) police aims generally practical situations in which it should intervene.

In Romania, the community police was founded in 2005 as a condition sine qua non related to the increase of autonomy of the local public administration and of course as a necessity inducted by our admission in the European Union and the increase of the role of the state.

\section{The local purpose and the fields of structures of the local police}

In the $1^{\text {st }}$ art. of the Law of local police the followings are stipulated: the local police is constituted with the purpose of carrying out main attributions of defending the fundamental rights and freedoms of the person, of private and public property, the prevention and discovery of crime, in the following fields:

- Public order and silence, as well as safety of citizens;

- Traffic on public roads;

- Discipline in intersections and street display;

a) Environment protection;

b) Commercial activity;

c) Listing of the population;

d) Other fields of activity appointed by law.

The local police functions in villages, towns, municipalities, sectors of municipality Bucharest and of course the capital.

The number of local police officers is according to the European Norm that states the report 1/1000, one police officer for 1000 inhabitants.

The organizational chart of each entity is decided by the local council of the community, as well as the main missions required by the territory and the population in the respective area.

\footnotetext{
${ }^{1}$ The Committee of Ministers of the European Council, The European Police Code of Ethics, Recommendation (2001) 10'19.08.2001, p. 31.

${ }^{2}$ The European Police Code of Ethics. Recommendation (2001)1. 19.09.2001 p. 24.
} 
Making a parallel between the Romanian police and the local police to show that the first is a reactive organ and, centralized and independent and the local police is a proactive organ decentralized which has close connections with the community. They act preventive and act as good householders.

\section{The subordination, coordination and management of the local police}

The local police are subordinated to the local council that is to the citizens of the town and must present quarterly and yearly information notes regarding its immediate activity. The local council decides performance assignments for the institution as well as the priorities given by the specific of the town.

The mayor coordinates closely the entire activity of the local police; he is in fact also the president of the commission for order and public safety and at the same time the one who approves yearly the plan for order and public safety of the town. On a monthly basis and each time necessary he is informed in written form about the results of the work and the objectives in the following period of time.

The mayor acts accordingly to the stipulations and obligations established by the Law of the local police.

The immediate and direct management of the local police is carried out by the General Manager or Executive Manager. He is helped by the Deputy Manager, Service and Office Managers, based on the yearly, monthly, weekly and daily plans. The integrative character of the work is defined also by the working procedures specific for the approximately 126 pointlike that should be fulfilled by a structure of the local police.

\section{Organization, facilities and the missions of the local police}

The local police is organized and functions by means of decision of the deliberative authorities of the local public administration, as a functional compartment within the special apparatus of the mayor or as a public institution of local interest. ${ }^{3}$

The number of positions, the personnel categories, the facilities, endowment as established through the Framework Regulations and Organizational and Functional Regulations of the local police issued by the local council. The facilities of the structure are realized according to the legal provisions but also according to the particularities and distinctiveness of the town and comprise the individual and collective facilities of the institution.

The provision of lethal, non-lethal facilities, with communication technique as well as auto means confers to the institution management and executive capacity. The missions result from the fields subsumed by law and are about 65 and the tactic ones are of approximately 130.

The main three missions with strategic character:

- Supervises that the law is respected

- Helps the persons that are in need, trouble;

- Helps the citizens in the relation with other private and state institutions, as well as with other citizens

\section{Working steps, cooperation and relation of the local police - of the local police} officer.

Strength, respect and appreciation of the local police consist in my opinion in the compliance with the procedural working steps, in the relation with the citizen of course. These are:

- Preventive notification

- Formal notice

- Warning

- Fine

\footnotetext{
${ }^{3}$ Law of the local police no. 155 from the $12^{\text {th }}$ of July 2010 , Art. 4 .
} 
No matter the field of responsibility there is the smallest risk for the agent to fall in the disgrace of the citizen if he complies with these steps and of course realizes them personally of by dispatch data base, from where he can extract information regarding the prior behavior antecedents.

For the fulfillment of missions the local police, the local police officer cooperates and relates with the citizen, with all institutions subordinated to the city hall, with the institution from the town, county as well as the institutions in the area of public order and safety and national defense.

There is no mission for which information or cumulated action is not needed that is why the relational linkage is mandatory.

\section{Legal competence and training of the local police officer}

The responsibility area of the local police officer from a legal point of view is from contravention downwards. The crime field exceeds directly the activity of the local police officer. He undertakes the first steps. Regarding the progressive training of the local police I can show that it is being realized through 3 methods: taking-out from production through brief summons at the working place.

It is important for the local police officer the need to train continuously by means of an own system so that at the end of the year he/she can quantify the new or the added value in the field of preoccupation as well.

\section{What aims to be the local police and the local police officer?}

The direct answer to this relative question is: a structure used by the town hall with a particular spirit, an institution close to the citizen and the police officer an esteemed public servant, appreciated, wanted and close to the citizen.

The profile of the local police officer must be ennobled by the biological, professional, social-human and behavior component.

\section{Conclusions}

The presented material can be seen as an invitation to deeper analyze of the role, purpose and missions of this new institution within the town halls or related with the town halls, so that the citizen can be informed through various ways regarding the lucrative areas of this service and the institution should take into consideration the expectations of the inhabitants of the community.

I consider through this presentation "the face" of this new institution was projected together with its multiple responsibilities and competences in a polychromatic and multiform area such as that of the public order and silence, street sanitation, environment, commercial control, in one word of the sum of arrangements and good order, the utility of the environmental and of the beauty.

\section{Bibliography}

Decision no. 1332 from the $23^{\text {rd }}$ of December 2010 regarding the approval of the Frame Rules governing the functioning and organization of the local police;

Law no. 155 from the $12^{\text {th }}$ of July 2010 of the local police;

The Committee of Ministers of the European Council, The European Police Code of Ethics, Recommendation (2001) 10 19.08.2001. 